\title{
PENERAPAN MANAJEMEN BERBASIS SEKOLAH DI SMP ADVENT 4 PAAL DUA
}

\author{
Joseph Philip Kambey \& Florence Olivia Moroki \\ Program Studi Manajemen, Fakultas Ekonomi, \\ Universitas Negeri Manado (UNIMA) \\ josephkambey@unima.ac.id
}

\begin{abstract}
Abstrak
Kegiatan Program Kemitraan Masyarakat (PKM) yang akan dilaksanakan pada SMP Advent 4 Manado ini bertujuan untuk membantu meningkatkan kemampuan kepala sekolah dan tenaga kependidikan dalam menghasilkan pendidikan yang berkualitas melalui penyelenggaraan pendidikan secara mandiri. Permasalahan mitra menunjukkan adanya kesamaan fenomena. Dalam kurun waktu lima tahun terakhir, belum ada prestasi yang dicapai oleh mitra sehingga membuat sekolah ini tidak menjadi salah satu tujuan utama masyarakat untuk menyekolahkan anaknya. Beberapa permasalahan tersebut terjadi oleh karena konsep manajemen berbasis sekolah yang merupakan strategi yang dapat dilaksanakan oleh sekolah untuk evaluasi diri serta menganalisa kekuatan dan kelemahan sekolah belum diimplementasikan. Tata kelola sekolah yang tidak baik pun masih terlihat dari rencana program sekolah termasuk pembiayaannya yang tidak mengacu kepada skala prioritas sesuai dengan kondisi sekolah dan sumber daya yang tersedia. Metode kegiatan yang akan dilakukan adalah ceramah, diskusi dan tanya jawab, serta pelatihan/workshop pada guru-guru. Hasil dari kegiatan ini adalah $90 \%$ guru-guru yang ada di SMP Advent 4 Paal Dua telah memahami dengan baik penerapan Manajemen Berbasis Sekolah. Diharapkan bahwa seluruh guru dapat menerapkan Manajemen Berbasis Sekolah di SMP Advent 4 Paal Dua.
\end{abstract}

Kata Kunci: Manajemen berbasis sekolah, tata kelola sekolah, monitoring, evaluasi.

\section{PENDAHULUAN}

Sekolah adalah bagian yang sangat penting dalam kehidupan masyarakat, karena dengan adanya sekolah kita sebagai masyarakat dapat memperoleh pendidikan yang baik. ia bukan merupakan lembaga yang terpisah dari masyarakat, hak hidup dan kelangsungan hidup sekolah bergantung pada masyarakat, sekolah adalah lembaga sosial yang berfungsi untuk melayani anggota2 masyarakat dalam bidang pendidikan, kemajuan sekolah dan masyarkat saling berkolerasi, keduanya saling membutuhkan. Organisasi sekolah adalah di dalamnya terdapat tim administrasi sekolah yang terdiri dari sekelompok orang yang bekerja sama dalam rangka mencapai tujuan oranisasi. Pengelolaan sekolah ini diberikan tidak lain dan tidak bukan adalah dalam rangka peningkatan mutu pendidikan.

Sejalan dengan belakunya otonomi daerah dalam dunia pendidikan, MBS atau school-based management (SBM) menuntut terjadinya perubahan dalam manajemen sekolah.Karena itu, pengelolaan suatu sekolah diserahkan kepada sekolah tersebut, atau sekolah diberikan kewenangan besar untuk mengelola sekolahnya sendiri dengan menggunakan 
Manajemen Berbasis Sekolah ini. Tujuan utama adalah untuk mengembangkan prosedur kebijakan sekolah, memecahkan masalah-masalah umum, memanfaatkan semua potensi individu yang tergabung dalam tim tersebut. Sehingga sekolah dapat mencetak orang yang cerdas serta emosional tinggi, juga dapat mempersiapkan generasi muda yang nantinya akan membangun negara dan bangsa yang lebih baik.

Sekolah Menengah Pertama (SMP) Advent 4 Manado terletak di Jalan Yos Sudarso No. 115 Paal Dua Manado Propinsi Sulawesi Utara. SMP Advent 4 Manado dengan luas tanah sebesar $1200 \mathrm{~m} 2$ (tanah hibah), memiliki 4 (satu) bangunan dengan luas $1000 \mathrm{~m} 2$, secara topografis berada di belakang kantor GMAHK Konferens Manado. SMP Advent 4 Manado pada saat ini dipimpin oleh seorang Kepala Sekolah yang bernama Drs. Hendro Pungus, M.Pd. Secara demografi, jumlah pendidik SMP Advent 4 Paal Dua adalah 22 (dua puluh dua) orang dengan jenjang pendidikan S1 dan S2, jumlah tenaga kependidikan adalah 2 (dua) orang dengan jenjang pendidikan S1, dan jumlah peserta didik sebanyak 470 orang yang dibagi dalam 3 (tiga) rombongan belajar (rombel).

Sarana dan Prasarana sekolah SMP Advent 4 Paal Dua yang tersedia adalah 13 (tiga belas) ruangan kelas, 1 (satu) ruangan Laboratorium, 1 (satu) ruangan Perpustakaan dan 1 (satu) ruangan kantor. Sarana olah raga SMP Advent 4 Paal Dua hanya memanfaatkan lahan yang ada di dalam sekolah. Pada saat ini SMP Advent 4 Paal Dua masih menggunakan Kurikulum KTSP.

Hasil survei dilapangan dan tanya jawab dengan bagian administrasi dan Kepala Sekolah kedua mitra menunjukkan adanya kesamaan fenomena. Dalam kurun waktu lima tahun terakhir, belum ada prestasi yang dicapai oleh mitra sehingga membuat sekolah ini tidak menjadi salah satu tujuan utama masyarakat untuk menyekolahkan anaknya. Ditinjau dari mutu pendidikan, secara umum masih rendah. Hal itu bisa dilihat dari batas standar lulus yang masih rendah. Pada saat ini SMP Advent 4 Manado masih menggunakan Kurikulum KTSP karena ketidaksiapan tenaga pendidik dalam menerapkan Kurikulum 2013 sehingga hal ini berdampak pada peningkatan mutu sekolah.

Beberapa permasalahan tersebut terjadi oleh karena konsep manajemen berbasis sekolah yang merupakan strategi yang dapat dilaksanakan oleh sekolah untuk evaluasi diri serta menganalisa kekuatan dan kelemahan sekolah belum di implementasikan. Tata kelola sekolah yang tidak baik pun masih terlihat dari rencana program sekolah termasuk pembiayaannya yang tidak mengacu kepada skala prioritas sesuai dengan kondisi sekolah dan sumber daya yang tersedia. Kegiatan yang tak kalah pentingnya yang tidak dilakukan secara optimal oleh mitra adalah kegiatan 
monitoring dan evaluasi internal program yang telah direncanakan.

Berdasarkan permasalahan tersebut maka dapat disimpulkan beberapa sumber permasalahan, yaitu:

1. Kepala sekolah dan tenaga kependidikan tidak pernah mengikuti kegiatan penyuluhan dan pelatihan manajemen berbasis sekolah;

2. Sekolah belum menerapkan prinsipprinsip tata kelola yang baik; dan

3. Tidak optimalnya pelaksanaan monitoring internal.

Berdasarkan permasalahan yang dihadapi mitra, maka solusi dari pelaksanaan program kegiatan PKM ini adalah sebagai berikut:

1. Meningkatkan pemahaman dan kemampuan kepala sekolah dan tenaga kependidikan dalam mengimplementasikan manajemen berbasis sekolah. Luaran yang dihasilkan berupa workshop dan draf modul manajemen berbasis sekolah;

2. Meningkatkan pemahaman dan kemampuan kepala sekolah dan tenaga kependidikan dalam menerapkan prinsip-prinsip tata kelola yang baik. Luaran yang dihasilkan workshop dan draf standar opersional prosedur pengelolaan sekolah; dan

3. Meningkatkan pemahaman kepala sekolah dan tenaga kependidikan tentang tata cara pelaksanaan monitoring dan evaluasi internal sekolah. Luaran yang dihasilkan adalah workshop dan draf skema monitoring dan evaluasi internal sekolah.

\section{TINJAUAN PUSTAKA}

\section{Pengertian Manajemen Berbasis Sekolah}

Istilah Manajemen Berbasis Sekolah (MBS) merupakan terjemahan dari "School Based Management", istilah ini pertama kali muncul di Amerika Serikat (Mulyasa, 2002 : 24) ketika masyarakat mulai mempertanyakan relevansi pendidikan dengan tuntutan dan perkembangan suatu strategi untuk memperbaiki mutu pendidikan melalui pengalihan otoritas pengembalian keputusan dari pemerintah pusat ke pemerintah daerah dan ke masing-masing sekolah, sehingga kepala sekolah, guru, orang tua peserta didik, dan masyarakat setempat mempunyai kontrol yang lebih besar terhadap proses pendidikan, dan juga mempunyai tanggung jawab untuk mengambil keputusan yang menyangkut pembiayaan personal, dan kurikulum sekolah.

Secara leksikal, Manajemen Berbasis Sekolah (MBS) berasal dari tiga kata, yaitu Manajemen, Berbasis, dan Sekolah. Manajemen adalah proses penggunaan sumber daya, secara efektif untuk mencapai sasaran. Berbasis memiliki kata dasar basis yang artinya asas atau dasar. Sekolah adalah lembaga belajar dan mengajar serta tempa memberikan dan menerima ilmu pengetahuan atau pelajaran secara formal. Berdasarkan makna leksikal tersebut, maka MBS 
dapat diartikan sebagai penggunaan sumber daya yang berdasarkan atau berasaskan pada sekolah itu sendiri dalam proses pengajaran atau pembelajaran (Nurkolis, 2003 : 1). Sedangkan Raynold mendefinisikan Manajemen Berbasis Sekolah (MBS) dengan tiga komponen utama: Pertama, delegasi otoritas decision making (pengambilan keputusan) ke pihak sekolah menyangkut program pendidikan termasuk kepegawaian, anggaran dan program. Kedua, penerapan model decision-maker bersama pada sekolah oleh tim manajemen termasuk kepala sekolah, guru, orangtua siswa, dan masyarakat. Ketiga, ekspektasi dimana MBS akan mendorong leadership sekolah untuk berupaya dalam perbaikan sekolah (Raynolds, 2004 : 3).

Menurut Sukiono dalam majalah fasilitator (2003 : 35) pada dasarnya Manajemen Berbasi Sekolah (MBS) merupakan manajemen yang transparan, memiliki akuntabilitas terhadap masyarakat, dan melibatkan stakholder dalam pengambilan keputusan. Senada dengan itu Depdikbud seperti dikutip Mulyasa (2002 : 12) mengemukan bahwa Manajemen Berbasis Sekolah (MBS) merupakan suatu penawaran bagi sekolah untuk menyediakan pendidikan yang lebih baik dan lebih memadai bagi para peserta didik. Sedangkan secara operasional Manajemen Berbasi Sekolah (MBS) dapat didefinisikan sebagai pelaksana fungsi-fungsi Manajemen semua komponen pendidikan di sekolah (Hari Sudradjad, 2005 : 42).

\section{Karakteristik Manajemen Berbasis \\ Sekolah}

Karakteristik Manajemen Berbasis Sekolah (MBS) bisa diketahui antara lain dari bagaimana sekolah dapat mengoptimalkan kinerja organisasi sekolah, proses belajar mengajar, pengelolahan sumber daya manusia dan pengolahan sumber daya yang lain dan pengelolahan administrasi (Mulyasa, 2002 : 29). Lebih lanjut Mulyasa mengutip pendapat BPPN dan Bank Dunia (1999), mengutipdari Fokus On School : The Future Organisation of Education Service for Student, Department Of Educations Australia (1990), seperti dikutip oleh Mulyasa (2002 : 39-30 mengemukakan karakterisitik Manajemen Berbasis Sekolah (MBS) dalam bentuk bagan sebagai berikut :

Tabel 1 : Karakteristik Manajemen Berbasis Sekolah (MBS)

\begin{tabular}{|l|l|l|l|}
\hline \multicolumn{1}{|c|}{$\begin{array}{c}\text { Organisasi } \\
\text { Sekolah }\end{array}$} & \multicolumn{1}{|c|}{$\begin{array}{c}\text { Proses belajar } \\
\text { mengajar }\end{array}$} & $\begin{array}{c}\text { Sumber daya } \\
\text { manusia }\end{array}$ & \multicolumn{1}{c|}{$\begin{array}{c}\text { amber daya dan } \\
\text { adminstrasi }\end{array}$} \\
\hline $\begin{array}{l}\text { Menyediakan manaje- } \\
\text { men organisasi kepe- } \\
\text { mimpinan transparan- } \\
\text { sional dalam mencapai } \\
\text { tujuan sekolah }\end{array}$ & $\begin{array}{l}\text { Meningkatkan kwali- } \\
\text { tas belajar siswa }\end{array}$ & $\begin{array}{l}\text { Memberdayakan } \\
\text { staf dan menempat- } \\
\text { kan personal yang } \\
\text { dapat melayani ke- } \\
\text { perluan siswa }\end{array}$ & $\begin{array}{l}\text { Mengidentifikasi sum- } \\
\text { ber daya yang diper- } \\
\text { lukan dan mengaloka- } \\
\text { sikan sumber daya } \\
\text { tersebut sesuai dengan } \\
\text { kebutuhan }\end{array}$ \\
\hline
\end{tabular}




\begin{tabular}{|l|l|l|l|}
\hline $\begin{array}{l}\text { Menyusun rencana seko- } \\
\text { lah dan merumuskan ke- } \\
\text { bijakan untuk sekolah- } \\
\text { nya sendiri }\end{array}$ & $\begin{array}{l}\text { Mengembangkan kuri- } \\
\text { kulum yang cocok dan } \\
\text { tanggap terhadap ke- } \\
\text { butuhan siswa dan } \\
\text { masyarakat sekolah }\end{array}$ & $\begin{array}{l}\text { Memiliki staf yang } \\
\text { memiliki wawasan } \\
\text { manajemen berbasis } \\
\text { sekolah }\end{array}$ & $\begin{array}{l}\text { Mengelolah dana } \\
\text { sekolah }\end{array}$ \\
\hline $\begin{array}{l}\text { Mengelola kegiatan ope- } \\
\text { rasional sekolah }\end{array}$ & $\begin{array}{l}\text { Menyelenggarakan } \\
\text { pengajaran yang efek- } \\
\text { tif }\end{array}$ & $\begin{array}{l}\text { Menyediakan kegiat- } \\
\text { an untuk mengem- } \\
\text { bangkan profesi pa- } \\
\text { da semua staf }\end{array}$ & $\begin{array}{l}\text { Menyediakan du- } \\
\text { kungan administra- } \\
\text { tif }\end{array}$ \\
\hline $\begin{array}{l}\text { Menjamin adanya komu- } \\
\text { nikasi yang efektif anta- } \\
\text { ra sekolah dan masyara- } \\
\text { kat terkait (School com- } \\
\text { munity) }\end{array}$ & $\begin{array}{l}\text { Menyediakan pro- } \\
\text { yang diperlukan siswa }\end{array}$ & $\begin{array}{l}\text { Menjamin kesejahte- } \\
\text { raan staf dan siswa }\end{array}$ & $\begin{array}{l}\text { Mengelolah dan } \\
\text { memelihara ge- } \\
\text { dung dan } \\
\text { na lainnya }\end{array}$ \\
\hline $\begin{array}{l}\text { Menjamin akan terpeli- } \\
\text { harannya sekolah yang } \\
\text { bertanggung jawab } \\
\begin{array}{l}\text { accountability) kepada } \\
\text { masyarakat dan peme- } \\
\text { rintah }\end{array}\end{array}$ & $\begin{array}{l}\text { Perogram pengem- } \\
\text { bangan yang diperlu- }\end{array}$ & $\begin{array}{l}\text { Kesejahteraan staf } \\
\text { dan siswa }\end{array}$ & $\begin{array}{l}\text { Memelihara } \\
\text { dung dan sarana } \\
\text { lainnya }\end{array}$ \\
\hline
\end{tabular}

Sumber : Mulyasa : 2002:39

Sementara menurut Baily (1991) seperti dikutip Sudarwan Danim (2006 : 29) terdapat sembilan karakteristik yang dimiliki oleh Manajemen Berbasi Sekolah (MBS) yaitu:

1. Adanya keragaman dalam pola penggajian guru. Istilah populernya adalah pendekatan prestasi dalam hal penggajian atau pemberian kesejahteraan lainnya;

2. Otonomi Manajemen Sekolah, sekolah menjadi sentral utama manajemen pada tingkat strategis dan operasional dalam kerangka penyelenggaraan program pendidikan dan pembelajaran. Sementara, kebijakan internal lain menjadi penyertaannya;

3. Pemberdayaan Guru secara Optimal, dikarenakan sekolah harus berkompetisi membangun mutu dan membentuk citra di masyarakat, guru-guru harus diberdayakan dan memberdayakan diri secara optimal bagi terselenggaranya proses pembelajaran yang bermakna;

4. Pengelolaan Sekolah secara Partisipatif. Kepala sekolah harus mampu bekerja dengan dan melalui seluruh komunitas sekolah agar masing-masing dapat menjalankan tugas pokok dan fungsi secara baik terjadi transparansi pengelolaan sekolah;

5. Sistem yang Didesentralisasikan. Di bidang penganggaran misalnya, pelaksanaan MBS mendorong sekolah-sekolah siap berkompetensi untuk mendapatkan dana dari masyarakat atau dari pemerintah secara kompetitif (block grant) dan mengelolah dana itu dengan baik;

6. Sekolah dengan pilihan atau Otonomi Sekolah dalam Menentukan Aneka Pilihan Program akademik dan nonakademik dapat dikreasi oleh sekolah sesuai 
dengan kapasitasnya dan sesuai pula dengan kebutuhan masyarakatlokal, nasional, atau global;

7. Hubungan Kemitraan (Partenership) antara Dunia Bisnisdan Dunia Pendidikan. Hubungan kemitraan itu dapat dilakukan scara langsung atau melalui Komite Sekolah. Hubungan kemitraan ini bukan hanya untuk keperluan pendanaan, melainkan juga untuk kegiatan praktek kerja dan program pembinaan dan pengembangan lainnya;

8. Akses terbuka bagi sekolah untuk tumbuh relatif mandiri. Perluasan kewenangan yang diberikan kepada sekolah memberi ruang gerak baginya untuk membuat keputusan inovatif dan mengkreasi program demi peningkatan mutu sekolah; dan

9. Pemasaran sekolah serta Kompetitif. Tugas pokok dan fungsi sekolah adalah menawarkan produk unggulan atau jasa. Untuk membangun citra mutu dan keunggulan lembaga.

\section{Prinsip Manajemen Berbasis Sekolah (MBS)}

Menurut Sukadi dalam majalah Fasilitator (III, 2003 : 22) mengemukakan sepuluh prinsip Manajemen Berbasis Sekolah yaitu: 1) keterbukaan, yakni manajemen dilakukan secara terbuka (transparan); 2) kebersamaan, yakni manajemen dilaksanakan secara bersama-sama oleh pihak sekoloah dan masyarakat; 3) berke- lanjutan, yakni manajemen dilakukan secara berkesinambungan dan berkelanjutan tanpa dipengaruhi oleh pergantian kepala sekolah; 4) menyeluruh, berarti manajemen dilakukan secara menyeluruh menyangkut seluruh komponen yang menjunjung dan mempengaruhi pencapaian tujuan; 5) pertanggung jawaban, berarti dapat dipertanggung jawabkan ke orang tua/wali siswa, masyarakat, pemerintah dan pihak-pihak yang berkepentingan; 6) demokratis, yakni berarti keputusan yang diambil berdasarkan musyawarah antar komponen sekolah dengan masyarakat; 7) kemandirian, yang berarti sekolah memiliki prakarsa atau inisiatif, dan inovasi dalam rangka mencapai tujuan; 8) berorientasi pada mutu, artinya upaya-upaya yang dilakukan sekolah selalu berdasarkan pada peningkatan mutu pendidikan; 9) pencapaian standar pelayanan minimal (SPM), berarti manajemen sekolah tersebut untuk mencapai standar pelayanan sekolah (SPM) secara total, bertahap dan berkelanjutan; 10) pendidikan untk semua, artinya semua anak memiliki hak memperoleh layanan pendidikan yang sama.

\section{Implementasi MBS (Menejemen Berbasis} Sekolah)

Implementasi MBS akan berlangsung secara efektif dan efisien apabila didukung oleh sumber daya manusia yang profesional untuk mengoperasikan sekolah, dan yang cukup agar sekolah mampu menggaji staf sesuai dengan fungsinya, sarana dan 
prasarana yang memadai untuk mendukung proses belajar mengajar, serta dukungan orang tua siswa atau masyarakat yang tinggi (Mulyasa, 2002:58).

Lebih lanjut Mulyasa (2002 : 59) mengemukakan, agar impelementasi Menejemen Berbasis Sekolah (MBS) dapat diterapkan secara menyeluruh di Indonesia pada umumnya dan di kabupaten/propinsi pada khususnya terkait kondisi sekolah pada saat krisis sekarang ini sangat bervariasi di lihat dari segi kualitas, lokasi sekolah dan partisipasi masyarakat (orang tua). Dan kondisi inilah tampaknya yang akan menjadi permasalahan yang rumit dan harus di prioritaskan penyelesaiannya pasca krisis. Oleh karena itu, agar manejemen berbasis sekolah (MBS) dapat di implementasikan secara optimal, baik krisis maupun pada pasca krisis dimasa mendatang, perlu adanya strategi dalam penerapannya. Semua pihak harus menyadari peran serta tanggung jawabnya secara sungguh-sungguh.

\section{METODE PELAKSANAAN}

Metode pelaksanaan dalam kegiatan ini ditentukan berdasarkan kesepakatan bersama dengan mitra. Adapun metode pelaksanaan ini terdiri dari 3 bagian, yaitu tahap persiapan, tahap pemrosesan, dan evaluasi hasil kegiatan.

\section{Tahap Persiapan}

Dalam tahap persiapan, kegiatan yang dilaksanakan adalah sebagai berikut:
1. Menentukan tujuan kegiatan. Tujuan kegiatan ini adalah untuk membantu meningkatkan kemampuan kepala sekolah dan tenaga kependidikan dalam menghasilkan pendidikan yang berkualitas melalui penyelenggaraan pendidikan secara mandiri;

2. Melakukan analisis situasi dan mengumpulkan data primer untuk mengidentifikasi permasalahan yang dihadapi oleh mitra; dan

3. Bersama dengan mitra, merumuskan permasalahan dan solusi yang akan dilakukan.

\section{Tahap Pemrosesan}

Pada tahap ini akan ditentukan kegiatan yang akan dilakukan, metode kegiatan, dan partisipasi mitra dalam kegiatan.

1. Rancangan kegiatan yang akan dilakukan, terdiri dari:

a. Memberikan penyuluhan konsep manajemen berbasis sekolah;

b. Memberikan penyuluhan dan pelatihan tata kelola yang baik yang terdiri dari pelatihan partisipasi, transparansi, akuntabilitas, efektivitas, dan efisiensi; dan

c. Memberikan pelatihan monitoring dan evaluasi internal manajemen sekolah.

2. Metode kegiatan yang akan dilakukan adalah: ceramah, diskusi dan tanya jawab, serta pelatihan/workshop pada masing-masing mitra; 
3. Partisipasi mitra dalam kegiatan ini adalah:
a. Menyiapkan lokasi kegiatan;
b. Kesiapan ikut serta dalam kegiatan dan mengkoordinir peserta (tenaga kepen-didikan) kegiatan; dan
c. Menyiapkan data-data yang dibutuhkan.

\section{Evaluasi Hasil Kegiatan}

Pada tahapan ini kegiatan yang dilaksanakan adalah melakukan monitoring dan evaluasi setelah 100 hari kerja terhadap kinerja kepala sekolah dan tenaga kependidikan, sejauh mana manajamen berbasis sekolah dan tata kelola sekolah kedua mitra telah diimplementasikan. Langkah yang dilakukan adalah dengan cara:

1. Menyebarkan angket kepada masingmasing peserta kegiatan untuk mendapatkan umpan balik dari mitra sehubungan dengan penerapan manajemen berbasis sekolah;

2. Melakukan uji petik atas tata kelola sekolah berdasarkan standar operasional prosedur yang dibuat; dan

3. Melakukan pendampingan dalam melakukan monitoring dan evaluasi internal sekolah.

\section{HASIL DAN PEMBAHASAN}

Kegiatan ini dilaksanakan pada hari Kamis, tanggal 6 September 2018 di SMP Advent 4 Paaldua, Kecamatan Paaldua Kota
Manado. Pelaksanaan ini mengikuti tahapan sebagai berikut:

1. Persiapan (Minggu I, II, III, dan IV, Bulan Juli 2018)

Pada tahap persiapan dilakukan beberapa kegiatan yaitu:

a. Penyusunan TOR

b. Konsultasi Departemen Pendidikan Daerah Konferens Manado dan Maluku Utara (Kantor GMAHK).

c. Penyusunan dan penggandaan mater pelatihan.

2. Orientasi Lapangan dan Permohonan Ijin ( 1 Agustus 2018)

Mengunjungi sekolah SMP Advent 4 Paaldua dan Kantor GMAHK Konfrens Manado dan Maluku Utara untuk menyampaikan maksud dan tujuan mengadakan kegiatan PKM Manajemen Berbasis Sekolah bagi guru-guru.

3. Pemberitahuan Pelaksanaan Kegiatan Pelatihan.

Memberikan undangan kepada guruguru SMP Advent 4 Paaldua untuk menghadiri pelaksanaan PKM Manajemen Berbasis Sekolah

4. Pelaksanaan Kegiatan Pelatihan Kegiatan pelatihan tentang Manajemen Kelas Berbasis Sekolah dilaksanakan pada tanggal 06 September 2018 dengan mengikuti pedoman seperti yang tertera pada tabel berikut ini: 
Tabel 1 Pedoman Pelaksanaan Kegiatan Pelatihan

\begin{tabular}{|c|c|c|c|}
\hline No. & Jam & Kegiatan & Pelaksana \\
\hline 1 & $08.00-09.00$ & Persiapan & Panitia \\
\hline 2 & $09.00-09.05$ & Doa Buka Kegiatan & Peserta \\
\hline 3 & $09.05-09.45$ & $\begin{array}{l}\text { Sambutan sekaligus membuka kegiatan pelatihan } \\
\text { dan sosialisasi tentang teknis pelaksanaan kegiatan }\end{array}$ & $\begin{array}{l}\text { Direktur Pendidikan } \\
\text { Panitia }\end{array}$ \\
\hline 4 & $09.45-10.00$ & Kudapan & Panitia \\
\hline 5 & $10.00-12.45$ & 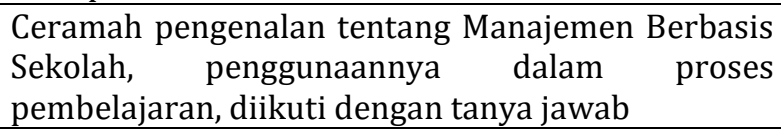 & Ketua Pelaksana \\
\hline 6 & $12.45-13.00$ & Makan Siang & Panitia \\
\hline 7 & $13.00-15.00$ & $\begin{array}{l}\text { Pembentukan Kelompok Diskusi untuk } \\
\text { mendiskusikan Manajemen Berbasis Sekolah }\end{array}$ & Ketua Pelaksana \\
\hline 8 & $15.00-15.15$ & Kudapan & Panitia \\
\hline 9 & $15.15-16.30$ & $\begin{array}{l}\text { Simulasi Manajemen Berbasis Sekolah yang } \\
\text { didiskusikan oleh setiap kelompok. }\end{array}$ & $\begin{array}{l}\text { Kelompok dan Ketua } \\
\text { Pelaksana }\end{array}$ \\
\hline 10 & $16.30-17.00$ & $\begin{array}{llll}\text { Tanggapan terhadap hasil simulasi tentang } \\
\text { Manajemen Berbasis Sekolah }\end{array}$ & $\begin{array}{l}\text { Kelompok dan Ketua } \\
\text { Pelaksana }\end{array}$ \\
\hline 11 & 17.00 & Selesai & \\
\hline
\end{tabular}

\section{KESIMPULAN DAN SARAN}

\section{Kesimpulan}

Adapun hasil kegiatan pelatihan ini berdasarkan hasil evaluasi kegiatan baik secara pengamatan maupun secara ujian tertulis. Pelaksanaan evaluasi melalui teknik pengamatan ini dilakukan selama berlangsungnya kegiatan pelatihan. Sedangkan evaluasi test (ujian tertulis) dilaksanakan pada akhir kegiatan pelatihan.

Berdasarkan hasil evaluasi kegitan ini maka diperoleh kesimpulan bahwa sebagian besar peserta pelatihan (90\%) telah memperoleh pengenalan pengetahuan tentang manajemen berbasis sekolah dan dapat melakukan dengan terampil kegiatan manajemen kelas dalam proses pembelajaran di kelasnya. Selain itu ditemukan sebagian kecil (10\%) dari guru guru sebagai peserta pelatihan yang masih memerlukan pemantapan latihan manajemen berbasis sekolah lebih lanjut.

\section{Saran}

Implementasi Manajemen Berbasis Sekolah dapat berhasil jika diawali dengan sosialisasi dari konsep Manajemen Berbasis Sekolah, identifikasi peran masing-masing, pembangunan kelembagaan, mengadakan pelatihan-pelatihan terhadap peran barunya, implementasi pada proses pembelajaran, evaluasi atas pelaksanaan di lapangan, dan dilakukan perbaikan-perbaikan.

\section{KEPUSTAKAAN}

Danim, Sudarwan, 2004, Visi Baru Manajemen Pendidikan Di Sekolah, Jakarta : Rineka Cipta

Hendarman, 2014, 'Kendala-Kendala Pelaksanaan Evaluasi Diri Sekolah (EDS)', Jurnal Pendidikan dan Kebudayaan, Vol. 20, No. 1, Maret 2014, Hal. $74-85$

Ihsan, Djailani, A.R \& Sakdiah I, 2014, 'Penerapan Manajemen Berbasis Sekolah Dalam Meningkatkan Mutu Pendidikan Di SD Negeri 62 Kota Banda 
Aceh', Jurnal Administrasi Pendidikan, Vol. 4, No. 2, November 2014, Hal. 12 20

Kementerian Pendidikan Dan Kebudayaan, 2013, 'Panduan Pelaksanaan Manajemen Berbasis Sekolah Di Sekolah Dasar', Jakarta

Kementerian Pendidikan Nasional, 2011, 'Manajemen Berbasis Sekolah', Pusat Pengembangan Tenaga Kependidikan Badan Pengembangan Sumber Daya Manusia Pendidikan Dan Penjaminan Mutu Pendidikan, Jakarta

Mulyasa, 2002, Menajemen Berbasis Sekolah; Konsep Strategi Dan Implementasi, Bandung : Remaja Rosdakarya.

Musbir, 2014, 'Pelaksanaan Manajemen Berbasis Sekolah Dalam Meningkatkan Mutu Pendidikan Di SMP Negeri 4 Peusangankabupaten Bireuen', Jurnal Ilmiah DIDAKTIKA, Vol. XIV No. 2, Februari 2014, Hal. 260-274

Nurkolis, 2003,Manajemen Berbasis Sekolah; Teori, Model, Dan Aplikasi, Jakarta : Grasindo

Raynold, Larry J, 2004, Kiat Sukses Manajemen Berbasis Sekolah, Pedoman Bagi Praktisi Pendidikan, Jakarta ; Diva Pustaka.
Slameto, 2011, 'Evaluasi Diri Sekolah Oleh Pemerintah Daerah', Jurnal Scholaria, Vol. 1, No. 2, September 2011, Hal. 1 21

Sudradjat, 2005, Hari, Manajemen Peningkatan Mutu Berbasis Sekolah; Peningkatan Mutu Pendidikan Melalui Implementasi KBK, Bandung : Cipta Lekas Garafika.

Suryosubroto, 2004, Manajemen Pendidikan Di Sekolah, Jakarta : Rineka Cipta

Trismanto \& Zainal, A.A, 2012, "Tata Kelola Sekolah Rsbi Serta Dampaknya Terhadap Kepuasan Dan Loyalitas Masyarakat', Jurnal Pendidikan Ekonomi Dinamika Pendidikan, Vol. VII, No. 2, Desember 2012, Hal. 140 - 153

Triwiyanto, T, 2015, 'Pelaksanaan Monitoring, Evaluasi, Dan Pelaporan Untuk Penilaian Kinerja Manajerial Kepala Sekolah', Jurnal Cakrawala Pendidikan, Th. XXXIV, No. 1, Februari 2015

Tyas, F.N \& Desi, N, 2014, 'Penerapan Program Evaluasi Diri Sekolah (EDS)', Jurnal Inspirasi Manajemen Pendidikan, Vol. 3 No. 3, Januari 2014, Hal. 89-99 